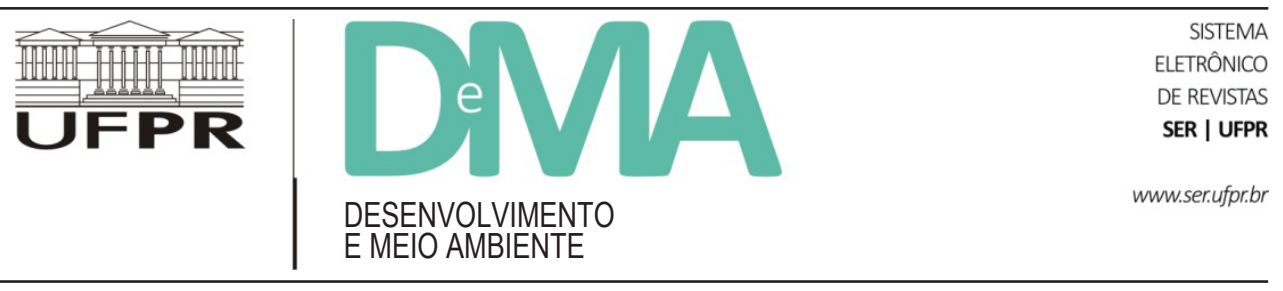

\title{
A representação social do Guará (Eudocimus ruber) nas falas e percepções das comunidades ribeirinhas de Guaratuba (PR): a educação ambiental necessária
}

\section{A Social Representation of the Guará (Eudocimus ruber) in Speech and Perceptions of the Local Population of Guaratuba Bay (PR): Environmental Education Required}

\author{
Francine Amelia Schaufelberger SCHERER ${ }^{1}$, Nelma BALDIN ${ }^{1 *}$ \\ ${ }^{1}$ Universidade da Região de Joinville (Univille), Joinville, SC, Brasil. \\ *E-mail de contato: nelma@univille.br
}

Artigo recebido em 12 de setembro de 2013, versão final aceita em 12 de dezembro de 2013.

RESUMO

O guará (Eudocimus ruber), ave típica da região de manguezais, permaneceu por um período de aproximadamente um século ausente do litoral do Estado do Paraná. Os fatores que levaram ao seu declínio no estado estão ligados diretamente a ações antrópicas. Em 2008, uma única ave da espécie foi avistada alimentando-se no manguezal de Guaratuba (PR). Após esse primeiro registro, bandos de guarás têm sido observados repovoando a região, especialmente a Baía de Guaratuba. A pesquisa aqui em destaque trata da representação social e do lugar que esta ave, o guará, ocupa no imaginário coletivo da população ribeirinha da Baía de Guaratuba. Trata-se, portanto, de uma atividade de Educação Ambiental. A pesquisa envolveu quarenta moradores ribeirinhos da localidade. O objetivo do estudo centrou-se na análise das questões históricas, comportamentais, sociais e ambientais que se relacionam com o desaparecimento do guará da Baía de Guaratuba, com ênfase no estudo das representações sociais e da simbologia da ave para o imaginário da população residente. O estudo desenvolveu-se na linha da pesquisa qualitativa etnográfica, sendo que foram efetuadas conversas informais pré-estruturadas com os moradores ribeirinhos. A análise das informações coletadas permitiu identificar as representações sociais e o imaginário coletivo sobre o guará para essas comunidades, remontado na alegria dos moradores pelo retorno da ave ao manguezal. Constatou-se a necessidade do desenvolvimento de ações de Educação Ambiental efetivas para a preservação da ave na região.

Palavras-chave: educação ambiental; guará (Eudocimus ruber); representação social.

ABSTRACT The guará (Eudocimus ruber), a typical bird of the region of mangroves, remained for a period of about a century away from the coast of Paraná. The factors that led to its decline in the state are linked directly to human actions. In 2008, a single bird of the species was sighted feeding in mangrove Guaratuba (PR). After this first record, flocks of guará have been observed repopulating the region, especially the Guaratuba Bay. The research 
highlighted here is the social representation and the place that this bird occupies in the collective imagination of the local population of Guaratuba Bay. It is, therefore, an Environmental Education activity. The research involved forty residents bordering the locality. The objective of the study focused on the analysis of historical issues, behavioral, social and environmental factors that relate to the disappearance of the guara in Guaratuba Bay, with emphasis on the study of social representations and symbolism of the bird to the imagination of the resident population. The study was developed in line with the qualitative ethnographic research, and informal pre-structured conversations were conducted with river dwellers. Analysis of the information collected allowed us to identify the social representations and collective imagination about guará for these communities, reassembled in the joy of the residents for the return of the bird in the mangrove forest. It was noted the need to develop effective environmental education actions to preserve the bird in the region.

Keywords: environmental education; Guará (Eudocimus ruber); social representation.

\section{Introdução}

Os indivíduos relacionam-se com o ambiente onde vivem de diferentes modos. Essa relação é construída no campo da interação social, onde esses sujeitos realizam suas práticas cotidianas. A cultura do lugar, os modos de vida e os costumes são fatores que moldam essa relação de proximidade entre o sujeito e a natureza. Essa forma de vivência pode ser observada na Baía de Guaratuba.

O município de Guaratuba, situado no litoral sul do Paraná, possui em seu território um patrimônio ambiental de grande beleza. O nome Guaratuba, de origem tupi Wa'ra: pássaro; guará tuba, sufixo coletivo de "muitos", ou seja, muitos guarás, revela que quando do início do povoamento da localidade havia ali abundantes bandos de guarás (Mafra, 1952). Ave de exuberante beleza, o guará (Eudocimus ruber), habitante de regiões costeiras, é encontrado nos manguezais da América do Sul, parte da Colômbia, Venezuela, Trinidad Tobago, Suriname, Guiana, Guiana Francesa e no Brasil (Olmos \& Silva e Silva, 2003)

O guará foi numeroso até meados do séc. XIX no litoral do Paraná e acabou por perpetuar sua memória em toda a região e, particularmente, nas cidades de Guaratuba e Guaraqueçaba, que garantem a sua presença em seus nomes, como se depreende da leitura de Carrano e Scherer Neto (2009). Como expressam esses autores, em decorrência de ações do homem, progressivamente os guarás foram desaparecendo dos manguezais paranaenses e, consequentemente, de toda a região sul do Brasil.

Guaratuba mantém uma estreita relação histórica, comportamental, social e ambiental com o guará. Confor- me Mafra (1952), desde o início da colonização da área as lindas penas da ave instigavam a cobiça dos homens, que desejavam obter lucros com a comercialização tanto de suas penas como de seus filhotes. Promoviam-se caçadas, assim como a retirada dos ovos dos ninhos, de modo indiscriminado, mesmo sob as proibições da Capitania, que tentava coibir tais ações justamente por temer a extinção da ave na baía, situação que posteriormente de fato aconteceu. Mafra (1952, p. 87) destaca, ainda, que eram permitidas a caça ou a captura de guarás apenas com "ordens expressas vindas da Coroa, pelo Vice-Rei, que enviava as aves à Europa”.

Em 1781, a Coroa Real fez publicar um edital proibindo a caça do guará em Guaratuba. O fragmento do edital original, publicado em Mafra (1952, p. 160), descreve:

Por constar a nós a noticia que várias pessoas das principais desta Vila lançam sem temor das ordens do Snr. General de Sam Paulo, mandadas observar envariavelmente pelo Dr. Antonio Barboza de Matos Coutinho, e já de antes pelo Sargento Mor Francisco Jose Monteiro, Comandante de Paranaguá, para que a pessoa de qualquer qualidade ou estado que forem, não poderem ir às ilhas desta Vila rio acima, onde costumam pernoitar par criar Guarazes, tão recomendados pela própria majestade e seus Generais, Governadores e Ministros, a tirarem-lhes os ovos com grande prejuízo de sua criação tão estimadas, e por nos constar que violando todas estas ordens sem o menor temor delas e de quem as administrava, entravam e mandavam entrar no passado ano nas ditas ilhas, várias pessoas tiraram todos os ovos não só seu gasto supérfluo mas sim para deles fazerem seus 
presentes a diferente país, até aqueles que deviam desviar que outros fizessem tal destroço na criação daqueles pássaros. Portanto, em observância das ordens tantas vezes recomendadas e ultimamente recebidas do Dr. Antonio Barboza de Matos Coutinho, Ouvidor Geral de Paranaguá, executor das ordens do Snr. General de São Paulo, somos servidos mandar publicar e afixar no lugar mais público desta Vila o presente edital para que chegue a notícia de mais lugares menores, que toda pessoa de qualquer qualidade que seja, inda que família for incorrera nas penas de seis mil reis de condenação, metade para o acusador e metade para as despesas da Câmera e na pena de prisão, remetidos logo a cadeia de Paranaguá, com porte de sua prisão ao Snr. General de São Paulo, para pelo dito Snr. serem punidos condenados a suas ordens. Dado e passado a 2 de outubro 1781.

Mafra (1952) informa, ainda, que três soldados do Regimento de Mexias que estavam em estudos em Paranaguá, os Alferes Manoel Gomes Marzagão, José Gonçalves e Antonio Carvalho Bueno, caçaram e abateram guarás, pelo qual foram punidos em 14 de maio de 1781, para que servissem de exemplo à população local.

A beleza do guará de fato impressiona quem o vê. O naturalista August de Saint'Hilaire, quando nos inícios do séc. XIX em viagem pelo litoral do Paraná e especialmente em Guaratuba, também destacou o seu encantamento em relação aos guarás que povoavam a região. O cientista revelou, em seus escritos, a existência das aves desde o Estado de São Paulo até Santa Catarina, mas faz uma referência especial ao fato de tais aves desovarem apenas na Baía de Guaratuba. Segundo seu relato, citado por Mafra (1952, p. 87), "no período de agosto a novembro os guarás se reuniam em grupos numerosos e então faziam seus ninhos às margens do mangue, em Guaratuba".

Devido às próprias barreiras naturais da localidade, Guaratuba permaneceu por um longo período de tempo isolada do restante da Capitania e, posteriormente, do Estado do Paraná, fato este que levou a sua população a adaptar-se às condições ambientais então ali existentes. Com um solo pobre, os moradores da localidade retiravam da natureza o que necessitavam para garantir a sobrevivência. E foi deste modo que foram sendo construídas as relações de dependência econômica e social da comunidade com o ambiente da Baía de Guaratuba.
Depois de um longo período de desaparecimento do local, por aproximadamente um século, em 2008 uma única ave da espécie guará foi registrada alimentando-se na Baía de Guaratuba (Instituto Guaju, 2012). Após essa primeira marca, outras observações foram possíveis na Baía Guaratuba, mas apenas de indivíduos isolados. Atualmente, há registros e imagens (fotografias e vídeos) de grupos de guarás repovoando a Baía de Guaratuba (Figura 1).

A população que vive às margens do ecossistema da Baía de Guaratuba tem estabelecido com os guarás uma relação de proximidade. Nessa direção, compreender como os indivíduos relacionam-se com o ambiente onde vivem torna-se uma ferramenta indispensável para o conhecimento das condutas assumidas por essa população.

O modo de pensar das pessoas atravessa a sociedade exteriormente aos indivíduos isolados e forma, com eles, um complexo, um conjunto de ideias e de motivações que já estão consolidadas. A forma de pensar está inserida num momento histórico-social que deve ser compreendido tendo em vista sua configuração coletiva específica, reflexiona Reigota (2007). Essa formatação, reflexiva, está presente na coletividade, mas constitui expressões socioculturais específicas e estilos peculiares de pensamento, os quais existem no contexto das ações coletivas.

Essas ações que tratam da realidade social são ratificadas pela teoria das representações sociais, que situa o poder da realidade social por meio da atuação dos sujeitos sociais. Por ser um elo entre o real, o psicológico e o social, as representações são capazes de estabelecer conexões entre a vida abstrata do saber e das crenças com a vida concreta do indivíduo e seus relacionamentos e trocas com os demais.

Nessa direção, denota-se que o estudo das representações procura compreender não só o que as pessoas pensam sobre um determinado assunto ou objeto que possua algum valor socialmente relevante, mas, também, procura entender por que os indivíduos pensam daquela forma (Andrade Junior et al., 2004).

Os modelos de organizações sociais carregam ainda outros aspectos fundamentais a serem observados, em especial no campo do imaginário. Segundo Serbena (2003, p. 2), esses campos do imaginário coletivo car- 


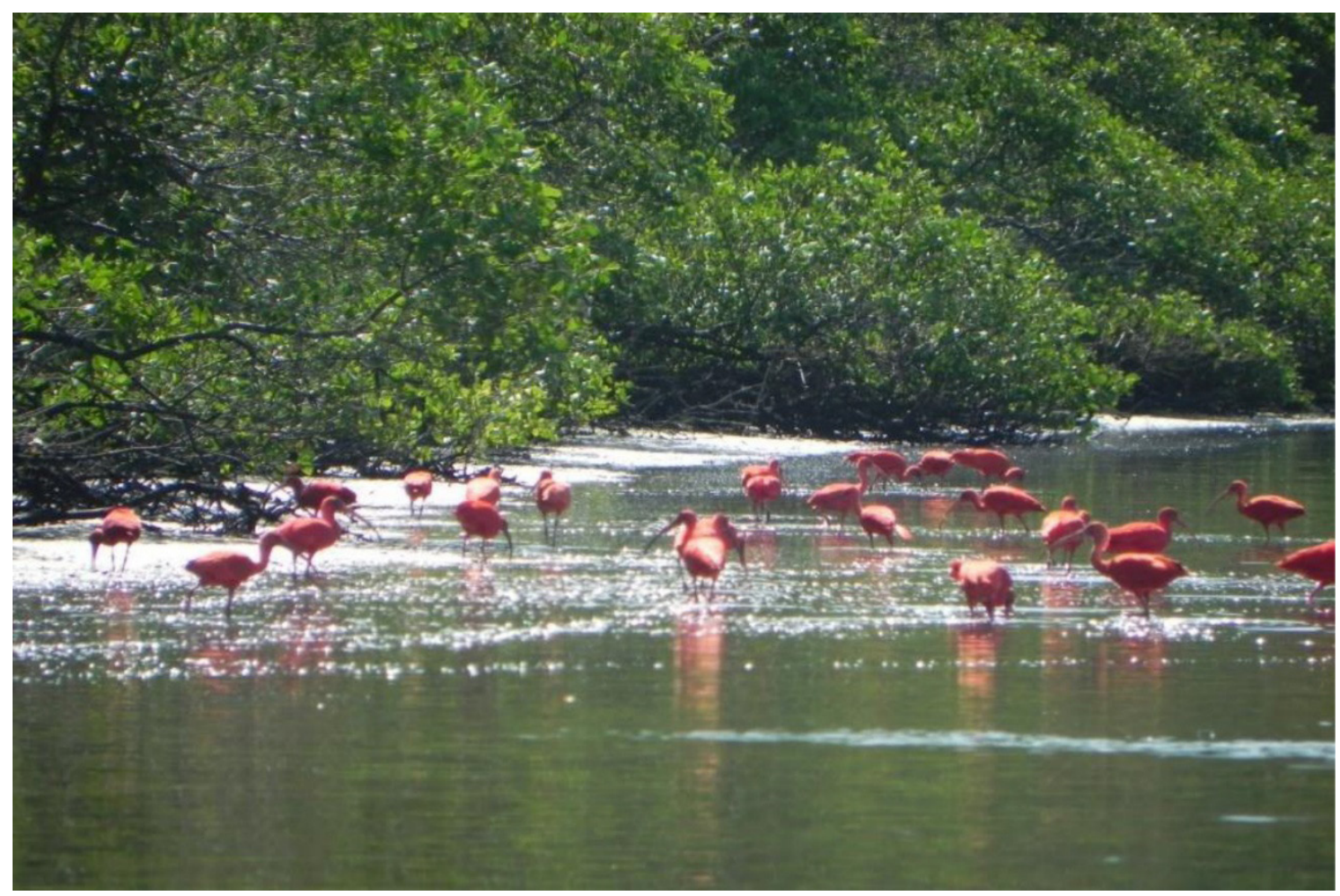

FIGURA 1 - Grupo de guarás alimentando-se na Baía de Guaratuba (2012).

FONTE: Imagem cedida pelo Instituto Guaju - Guaratuba (PR).

regados de representações sociais são "formados pelas imagens, símbolos, sonhos, aspirações, mitos, fantasias pré-racionais, com forte conotação afetiva que existem e circulam nos grupos sociais".

Ferreira e Eizirik (1994) explicam que o imaginário social distingue a imaginação individual dos grandes simbolismos que subsistem nas culturas. O imaginário social não é resultante das decisões estritamente racionais, pois as ideologias, as estruturas sociais, os sistemas de representação coletiva asseguram a coesão social. O conjunto de normas e valores culturais se materializa nas práticas sociais, nos processos de identificação, nos arranjos grupais, além de reforçar e intuir elos sociais entre eles. Esse processo se relaciona ao imaginário coletivo e às representações sociais de uma simbologia, de um mito ou de um fenômeno da realidade.
Serbena (2003 p. 2) esclarece, ainda, que "os mitos e os símbolos podem se tornar receptores de interesses, medos, aspirações e podem moldar comportamentos, condutas e visões de mundo". Entende o autor que, uma vez partilhado, o imaginário coletivo pode criar uma comunidade de sentido, podendo ainda solidificar-se, vindo a determinar uma visão de mundo ou uma representação social da coletividade.

As representações sociais e o imaginário popular podem fornecer uma mudança social tanto no nível individual como no coletivo. Jodelet (2009, p. 695) esclarece que "o modo de ver, pensar, conhecer, sentir e interpretar seu modo de vida e seu estar no mundo tem papel indiscutível na orientação e na reorientação das práticas coletivas". Nesse entendimento, ainda, Andrade et al. (2004) definem que as representações 
sociais tornam-se mais aparentes em tempos de grandes mudanças sociais, as quais sensibilizam a opinião do cidadão comum.

Esse encaminhamento, teórico, possibilita um estudo mais abrangente da relação, implícita, da representação social do guará no imaginário da população de Guaratuba. Para tanto, torna-se necessário estabelecer um limite de esclarecimento para o funcionamento da realidade. Esta é uma conduta social favorável que garante a vida e, em consequência, a preservação de todas as espécies vivas do planeta. O conceito introjetado de representação social e imaginário popular é fundamental para subsidiar o estudo das representações que a população de Guaratuba tem estabelecido com a ave guará, pois a relação homem-ave, no caso, perpassa o imaginário popular (coletivo) e os conceitos individuais, chegando-se a uma atitude bem mais comprometida individual e socialmente.

A pesquisa de que trata este artigo, portanto, foi aplicada junto à população ribeirinha da Baía de Guaratuba (PR) com o objetivo de analisar as questões históricas, sociais, comportamentais e ambientais que envolveram o desaparecimento do guará da localidade e, agora, de seu retorno a essa mesma baía, com ênfase no estudo das representações sociais e da simbologia da ave no imaginário da população ali residente. Além, ainda, da constatação da necessidade de desenvolvimento de ações práticas de Educação Ambiental junto a essa mesma população.

\section{Metodologia}

A pesquisa surge em sua essência a partir da inquietação do espírito humano. O desejo do saber, de conhecer e de compreender a realidade que o cerca move o homem a buscar as respostas que ainda não possui ou de aprimorar as já existentes.

Nesse entendimento, configura-se que o objeto desta pesquisa está relacionado com o campo das ciências sociais, das teorias sociais e da educação, uma vez que se situa na esfera das atividades cotidianas e comuns da vivência humana. O estudo reflete a visão social de mundo de um grupo determinado, pois "a construção da ciência é um fenômeno social", onde a pesquisa e o pesquisador são marcados pelo seu tempo e sua realidade histórica (Lüdke \& André, 2007, p. 2).

A pesquisa em evidência, portanto, está caracterizada como exploratória e descritiva e pode ser conceituada como uma pesquisa de abordagem qualitativa etnográfica, tendo em vista que envolve "dados descritivos obtidos a partir do contato direto do pesquisador com a situação estudada, enfatiza mais o processo do que o produto e se preocupa em retratar a perspectiva dos participantes" (Lüdke \& André, 2007, p. 13).

Para a realização da pesquisa, buscou-se identificar e selecionar grupos que representam a população que vive na região rural e ribeirinha da Baía de Guaratuba. Essa população é estimada, atualmente, em aproximadamente 3.292 pessoas, distribuídas em 36 localidades. Do total dessas localidades, foram selecionados quatro pontos especiais para a realização da pesquisa. Esses locais são considerados pontos geográficos estratégicos de Guaratuba porque abrangem uma vasta extensão territorial e são onde se apresentam, atualmente, as maiores probabilidades de se encontrar o guará ou os seus ninhais: Parati, Riozinho, Fincão e Cubatão (Figura 2).

Cada uma dessas localidades definidas para o estudo participou com um número representativo de 10 pessoas. A essa população selecionada para a pesquisa aplicou-se uma prática educativa, com base nas noções teóricas da Educação Ambiental, conforme orientações de Guimarães (2006) e de Floriani e Knechtel (2003), e também um diálogo em forma de uma conversa informal pré-estruturada. Essas 10 pessoas, cidadãos residentes em cada um dos quatro pontos estudados, perfizeram um total de 40 sujeitos dentre todos aqueles moradores que aceitaram participar da pesquisa. De início, fez-se uma reunião explicativa da pesquisa - aberta a todos os residentes - em cada uma das quatro comunidades. Nessas reuniões, definiram-se os participantes, sendo que os mesmos prontificaram-se a atuar voluntariamente nos procedimentos da pesquisa, assinando o Termo de Consentimento Livre e Esclarecido (TCLE). Com essa atitude, respeitaram-se as normas definidas pelo Comitê de Ética em Pesquisa da instituição que aprovou o projeto da pesquisa.

Para a realização das atividades da pesquisa via as conversas informais pré-estruturadas nas localidades de Fincão e Parati, bastou a presença das pesquisadoras 


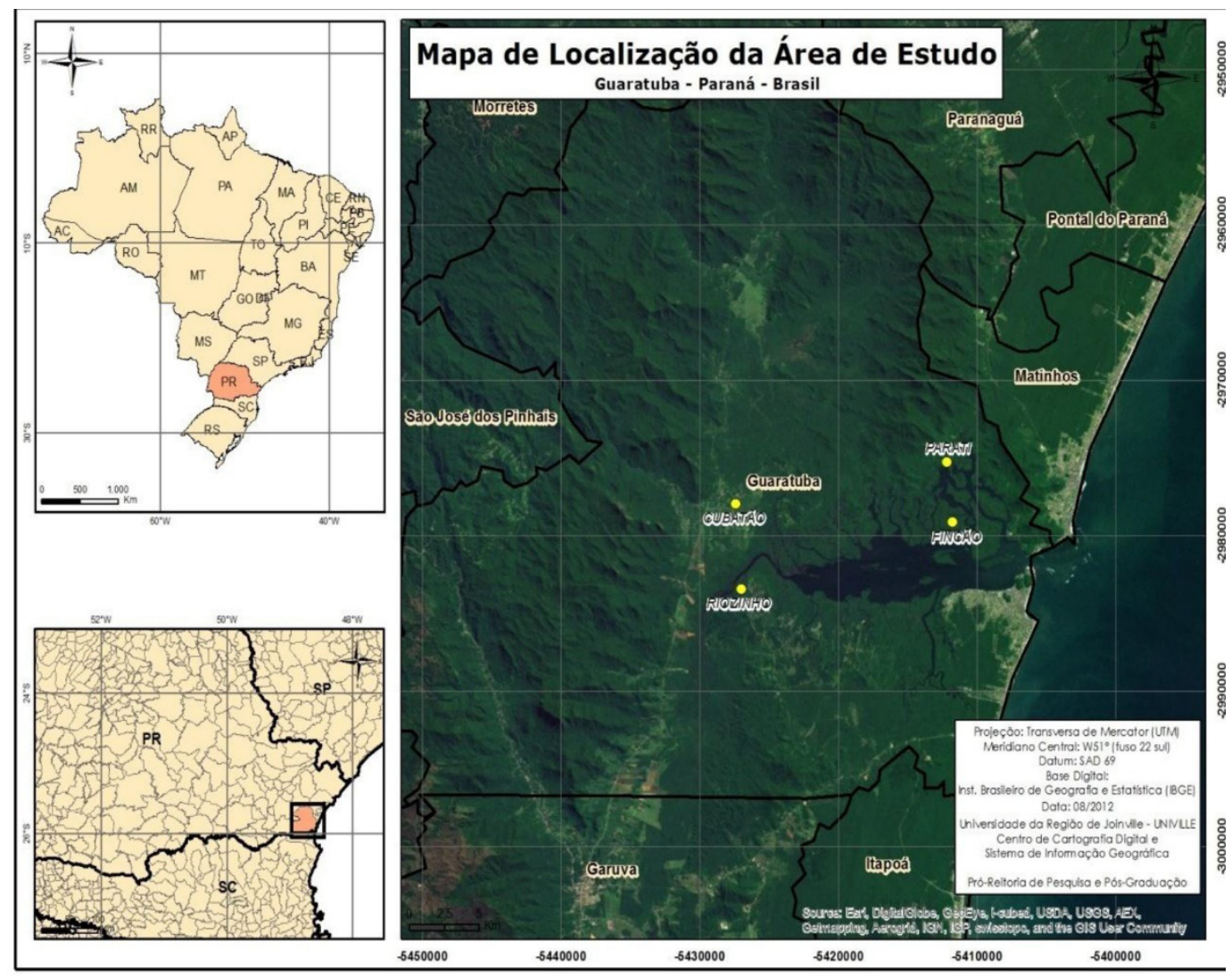

FIGURA 2 - Localização dos pontos onde foi realizada a pesquisa: Cubatão, Riozinho, Parati e Fincão (Guaratuba - PR). FONTE: Departamento de Cartografia da Univille - Joinville (SC) - 2013.

mais o barqueiro que as conduziu, uma vez que o acesso a essas localidades somente se faz por barco. Já para a prática da pesquisa nas localidades de Cubatão e Riozinho foi necessário que as pesquisadoras estabelecessem uma parceria com a EMATER com o objetivo da realização da ação proposta, e contando, assim, com a participação de um técnico, que passou a fazer parte da equipe nas atividades de campo, quando também se fez necessário o uso do barco para o acesso às comunidades.

Decorrente da leitura atenta do material coletado e das informações obtidas com os ribeirinhos, via as conversas informais pré-estruturadas, abstraíram-se as categorias de análise da pesquisa, entendidas, neste estudo, como as citações mais repetidas pelos participantes. Assim, os termos que mais foram enfatizados pelos voluntários caracterizaram a emergência de uma categoria de análise presente na fala dos sujeitos. No estudo, as categorias foram destacadas a posteriori, ou seja, emergiram da análise dos dados e informações coletadas durante a aplicação da pesquisa (Bardin, 2011).

Para chegar-se às categorias de análise que simbolizam a representação social que têm os participantes da pesquisa em relação à ave guará, procedeu-se da seguinte maneira: construiu-se um quadro mural, onde cada uma das localidades estudadas (Parati, Fincão, Riozinho e Cubatão) foi dividida em 10 colunas, num total de 40 colunas (uma coluna para cada participante), com 13 linhas - número de questões que foram discutidas nas conversas com os ribeirinhos que participaram do estudo. Previamente, definiu-se que os "termos" mais 
enfatizados e repetidos em determinada questão fossem transcritos para o quadro mural, na lacuna correspondente. Assim, os "termos" mais utilizados pelos participantes em todas as questões propostas formaram um conjunto de palavras-chave que se referiam ao "tema" da pesquisa e ao seu objeto de estudo. Os termos mais utilizados pelos participantes da pesquisa referiram-se especialmente às impressões do imaginário popular e da representação social do guará para essas comunidades.

Decorrentes desse procedimento metodológico, emergiram as categorias de análise, a posteriori, e que referendaram todo o estudo: sobrevivência - caça e coleta de ovos; desconhecimento; o belo e a beleza; símbolo.

Para um melhor entendimento do leitor, explicita-se, aqui, que na análise dos resultados da pesquisa os moradores ribeirinhos são representados pela letra " $R$ ", seguida de números de 1 a 40, exemplo: "R 18", sendo que de 1 a 20 representam as localidades Cubatão e Riozinho, nessa ordem, e de 21 a 40 são os ribeirinhos do Fincão e Parati, respectivamente, sendo 10 ribeirinhos de cada uma das quatro comunidades.

\section{Resultados e discussão}

Os moradores ribeirinhos da Baía de Guaratuba que participaram da pesquisa foram, originalmente, formados por dois grupos distintos em seus modos de vida, costumes e fontes de subsistência. O primeiro grupo foi formado por moradores das localidades Fincão e Parati, comunidades essencialmente constituídas por pescadores que vivem de modo simples e que retiram seu sustento de dentro da Baía de Guaratuba. Suas principais atividades são a pesca, o cultivo de ostras e de camarões. O meio de transporte utilizado para se chegar a essas comunidades é somente o barco. Estão localizados em uma região cercada pelas árvores - fechadas - da Mata Atlântica e é comum, aos sábados, os pescadores levarem seus peixes para serem comercializados nas imediações do Mercado Municipal, no centro de Guaratuba. São poucas as famílias residentes nessas localidades, especialmente devido ao isolamento e aos poucos recursos de saúde, educação e trabalho que por ali predominam. O segundo grupo, composto por moradores das localidades Cubatão e Riozinho, são agricultores e vivem na zona rural de
Guaratuba, entre a Baía de Guaratuba e a Serra do Mar. Como se lê nas anotações do caderno de campo das pesquisadoras, essas comunidades dependem essencialmente do cultivo da banana, da aposentadoria dos mais idosos e de programas de apoio do Governo Federal. Em alguns casos, como uma alternativa e incremento ao orçamento doméstico, determinadas famílias retiram da natureza a palha de palmeira ornamental para venda, tendo em vista que esse material é adquirido por floriculturas da região e especialmente por aquelas da cidade de Curitiba, a capital do Estado do Paraná.

Na população classificada como do primeiro grupo (pescadores de Fincão e Parati), foi possível identificar que um número expressivo de seus membros (cerca de $70 \%$ ) possuem conhecimento, mesmo que rudimentar, sobre as aves e a fauna local, pois reconhecem e nomeiam espécies de aves, mamíferos e répteis que vivem ao seu redor. Esses moradores expressaram que o retorno e a presença do guará na Baía de Guaratuba são motivos de grande satisfação.

Para essas duas comunidades ribeirinhas, o guará tem uma forte representação social, significa a volta de um símbolo vivo da história e de preservação da baía e da cidade. A baía é sinônimo de riqueza e alimento e preservá-la para a garantia da manutenção desse alimento ou da sua beleza (como é o caso do guará) é fundamental. Esse retorno do guará à baía mostra à sociedade como um todo que Guaratuba preserva sua natureza e que aqui é um "pedaço de paraíso", e a volta da ave que há muito havia desaparecido do seu ambiente natural reforça esse pensamento de que vale a pena "viver no paraíso", como expressou "R 30", um dos participantes ouvidos durante a pesquisa. É esta, de fato, a força da representação da presença da ave no imaginário coletivo dessas populações.

As formas de interpretar, compreender, categorizar, sentir e ler o mundo são produzidas nos processos de interação social dos homens via comunicação, trabalho, cultura, enfim, na vida cotidiana. Essas manifestações tornam-se expressões de uma dada sociedade ou de um determinado grupo social, dentro de um momento histórico específico. Tornam-se também formas de mediação e interação social, pois será por meio delas, das manifestações, que os sujeitos se relacionam e atuam em suas comunidades. 
Para os sujeitos dessas duas comunidades estudadas, o guará, além de ser um dos principais símbolos da cidade, representa, entre outros atributos, a beleza da baía, da praia, da floresta e de outros pontos locais. A ave empresta sua imagem para demonstrar um dos muitos atributos positivos presentes na região. O guará encanta e chama a atenção especialmente pela sua plumagem vermelha, que pode ser vista ao longe, e que desperta sentimentos profundos de admiração, contemplação e alegria.

A grande maioria desses ribeirinhos (em torno de $70 \%$ ) reconhece que uma das possíveis razões do desaparecimento do guará da Baía de Guaratuba tenha sido a caça que, segundo eles, é hoje um hábito abandonado. Porém, ao serem indagados sobre o antigo hábito de comerem ovos de aves silvestres, e dentre essas aves também os ovos do guará, esses cidadãos relataram que essa era de fato uma prática comum há alguns anos, mas que atualmente não é mais usual, principalmente porque, de fato, há tempos já não mais existem ninhos e nem ovos de guarás na região. Mas, segundo um participante da pesquisa ("R 38"), muitas pessoas ainda costumam comer ovos de aves silvestres, embora nos últimos cinco anos esse hábito tenha diminuído, além de que, como é do conhecimento de todos, tal prática constitui-se, hoje, em crime ambiental.

Os sujeitos demonstraram ter consciência de que essas atitudes e comportamentos de caça indiscriminada e coleta de ovos das aves, mesmo sendo de características culturalmente comuns e de certo modo socialmente aceitos na localidade, constituíam-se, na verdade, em dano ambiental e que não tem mais sentido ainda praticá-las. É esta a questão do "despertar" para uma consciência ecológica (Baldin \& Albuquerque, 2012).

Jacobi (2005, p. 241) adverte:

a postura de dependência e de não responsabilidade da população decorre principalmente da desinformação, da falta de consciência ambiental e de um déficit de práticas baseadas na participação e no envolvimento dos cidadãos, que proponham uma nova cultura de direitos baseada na motivação e na coparticipação na gestão do meio ambiente, nas suas diversas dinâmicas.

Já em relação ao segundo grupo (os agricultores de Cubatão e Riozinho), esses, em sua grande maioria, em torno de $80 \%$, são pessoas com poucos recursos financeiros e que, em alguns casos, vivem em casas de chão batido e demonstraram ter falta de comida, saúde, transporte e educação, dentre outros serviços fundamentais. Nessas residências, foi possível perceber que os que ali habitam vivem em situação precária, chegando mesmo próximos da miséria.

Como está registrado no caderno de campo das pesquisadoras, observou-se que em geral as plantações de banana chegam até os arredores das residências dessas pessoas, não existindo, ali, espaço para a criação de animais domésticos ou outros espaços para o cultivo de hortaliças para subsistência ou, mesmo, para o plantio de outras espécies vegetais economicamente viáveis. Quando questionado pelas pesquisadoras sobre essa situação, o técnico da EMATER que acompanhava o grupo nessa incursão informou que culturalmente esses sujeitos sempre retiraram da natureza o que necessitavam para sua subsistência e, assim, mesmo na atualidade, ainda não romperam com esse modelo extrativista predatório. E esse técnico ainda enfatizou: "mesmo que estejam recebendo apoio técnico, informações e recursos financeiros oriundos da própria EMATER ou do Governo Federal, essas populações continuam com essa prática".

Ao serem indagados sobre o guará, um número significativo de moradores (em torno de 70\%) respondeu que não conhecia a ave, que nunca a tinham visto e que não possuíam nenhuma informação de sua existência em suas propriedades ou imediações. Neste sentido, revelaram um total desconhecimento de quaisquer relações que o guará tenha estabelecido ou estabelece com a população de Guaratuba. Demonstraram não cultivar nenhuma representação social em relação à ave, chegando, mesmo, a questionar as pesquisadoras sobre a existência da ave guará: não seria o conhecido lobo guará? E veja-se que a pergunta veio de "R 10", um morador que já havia visto o animal (o lobo) na TV em determinada ocasião que fora à cidade.

Observou-se, nessa população, que para um número expressivo deles (cerca de $70 \%$ ) a ave guará não tem nenhuma representatividade, não povoa o seu imaginário e seu retorno à Baía de Guaratuba não lhes significa absolutamente nada. O campo de interesse e de ação social desses indivíduos é restrito e limitado. Ficou perceptível que, além de não possuírem o conhecimento sobre a ave 
e seu significado histórico e social para Guaratuba, essa população também não demonstrou interesse algum em vir a conhecer a ave.

De certo modo, esse fenômeno pode ser entendido. A distância que separa a cidade dessas localidades é muito grande, o isolamento geográfico é significativo somente se chega a essas regiões de barco - e o acesso à cultura e à informação é restrito. Nessas condições, as decorrências culturais dessas comunidades, bem como suas percepções e convicções em relação ao meio ambiente, são baseadas apenas na garantia de sua sobrevivência.

\subsection{A sobrevivência - caça e coleta de ovos de aves silvestres - os ovos do guará}

Os relatos dos ribeirinhos durante a aplicação da pesquisa confirmam que de fato a caça era uma prática muito frequente em anos atrás na Baía de Guaratuba. Eram caçados animais silvestres e aves de todo tipo, de modo indiscriminado. O objetivo fundamental dessa caça era, de maneira geral, para a alimentação e manutenção das famílias. Historiadores locais destacaram ainda que também pessoas de outras localidades vinham até o município de Guaratuba para caçar e pescar esportivamente. Um participante, "R 12", comenta sobre a prática.

Quando a gente era criança, era bem comum a gente caçar por aí, principalmente passarinho. Caçava de tudo, caçava muito. Não tinha tanto passarinho como tem agora, aqui na beirada da baía, hoje tem de monte. Pensa esses dias tinha um monte de papagainho aqui no trapiche, coisa mais linda. Sabe hoje se a gente fala para os netos da gente pra ir caça pardal, eles ficam bravos com a gente, falam que não pode, que isso destrói a natureza. Mas a gente quando era pequeno fazia, porque nem sabia que isso existia.

$\mathrm{Na}$ fala desse participante é possível estimar que, com a diminuição da prática da caça, houve um aumento na população de aves que habitam a baía. Porém, fica-nos evidente que mesmo sendo indiretamente educado ambientalmente pelos familiares (no caso, os netos), parece que esse conhecimento produz pouco ou nenhum efeito na vivência diária desse ribeirinho.
Este comportamento cultural encontrado nessas localidades também é destacado pelo participante "R 1" que enfatiza ser a caça uma prática comum já desde a década de 1950.

\begin{abstract}
Muita gente caçava aqui em Guaratuba, eu mesmo saía com o pessoal pra caçar. Caçava de tudo: cateto, veadinho, tatu, tudo quanto é bicho. A gente caçava pra comer. Sempre teve gente que vinha de longe pra caçar aqui no mato. E pegava de tudo.
\end{abstract}

Observa-se, portanto, que a degradação ambiental, basicamente, "ocorre por razões econômicas. As florestas são desmatadas para que produzam lucros com a venda da madeira. As espécies são caçadas para consumo pessoal, comércio e lazer" (Primack \& Rodrigues, 2001, p. 38).

$\mathrm{Na}$ verdade, no que se refere à coleta de ovos de aves silvestres para a alimentação da população ribeirinha, embora haja manifestação de participantes no sentido de expressarem que esta prática atualmente não mais existe na região, cerca de $30 \%$ dos ribeirinhos falaram que esta é uma prática ainda comum nas margens da Baía de Guaratuba até os dias atuais. Essa prática, passível de observação durante as incursões das pesquisadoras na baía, acontece especialmente devido à grande extensão territorial e também pela facilidade na obtenção dos ovos. Pelo valor nutricional e, em alguns casos, pela necessidade financeira, percebeu-se que o consumo desses ovos continua "bastante intenso", mesmo que tal ato ocorra de forma "escondida e mascarada", enfatiza " $\mathrm{R}$ 16", um dos participantes da pesquisa.

Segundo a participante "R 14", a coleta de ovos era uma prática muito comum desde antes da década de 1960:

\begin{abstract}
Quando a gente era criança saía de barco com meu pai pra pescar na baía. Na volta a gente recolhia os ovos de garças e de tudo quanto era passarinho que fazia ninho na beirada. Era uma panelada enorme que minha mãe cozinhava pra gente comer. Tenho saudades dessa época. Sabe, naquela época a gente não pensava em cuidar dos animais, e nem de aves e nem de florestas e nem de rios, a gente não tinha noção que isto podia desaparecer.
\end{abstract}


E "R 17” confirma que de fato essa era uma prática comum entre as famílias de Guaratuba nesse período:

Meu pai quando saía com meu avô pra pescar na baía, sempre voltava com um saco cheio de ovo de garças. Eu lembro que a mãe cozinhava uma panelada de ovos azul prá nós. Eu não comia porque eu não gostava, mas meus irmãos gostavam muito. E muitas vezes eles iam recolher aqui próximo de casa.

Os relatos desses participantes reforçam que esse hábito está perpetuado nos costumes da localidade e arraigado à cultura local. Foi possível observar que esses participantes falam com certo saudosismo desse período, quando esses comportamentos predatórios eram ainda hábitos comuns da localidade e não se constituíam socialmente como crimes ambientais. Viam esses comportamentos como "normais", pois as aves eram abundantes, enquanto que outros recursos de subsistência eram restritos.

Alguns dos participantes destacaram que, mesmo com iniciativas de Educação Ambiental realizadas pela Prefeitura e outras instituições públicas e privadas com vistas à conservação ou preservação ambiental, é possível perceber que de certa forma determinadas ações tradicionais e atitudes predatórias com relação ao meio ambiente não se modificam nas novas gerações. Os jovens repetem e perpetuam culturalmente os hábitos já consolidados, que são passados de pai para filho e estão arraigados no processo socioeducacional dessas populações. Neste contexto, entende-se necessário intensificar as iniciativas locais de preservação ambiental e de geração de renda ambientalmente sustentáveis para a formação de novos paradigmas que garantam efetivamente a preservação das espécies e, no caso deste estudo, a preservação do guará.

\subsection{O desconhecimento e o conhecimento}

Durante todo o processo de conversas informais acontecido junto aos habitantes ribeirinhos da Baía de Guaratuba, e com mais expressividade nos pontos Cubatão e Riozinho, ficou-nos evidente o desconhecimento dessas populações em relação à existência da ave guará em Guaratuba. Em torno de $70 \%$ das pessoas que foram contatadas nesses pontos não sabiam e não conheciam o guará e nem as relações que a ave estabeleceu e estabelece com o município de Guaratuba. Também demonstravam possuir pouco ou nenhum conhecimento sobre a história ambiental de seu município e a relação histórica ambiental que o município mantém com sua ave símbolo, o guará.

O participante "R 3" quando questionado sobre se conhecia ou não o guará e se poderia descrevê-lo para as pesquisadoras, respondeu: "Eu nunca vi, nem sei se existe esse bicho por aqui, também não sei como ele é”.

$\mathrm{Na}$ sua resposta, o participante deixa explícito seu desconhecimento e também demonstra pouco interesse em envolver-se com o ritual da pesquisa e/ou conhecer a história do guará em Guaratuba. Elias (1998) enfatiza que a maneira com que os indivíduos de um grupo vivenciam qualquer coisa que afete seus sentidos ou o significado produzido a partir da vivência que têm depende de fenômenos que gradualmente se desenvolveram em suas sociedades, ou do pouco pensar, refletir e falar sobre esses fenômenos. E como essas populações desconhecem a ave, têm pouco interesse em falar sobre a mesma.

Quando indagado sobre quais as possíveis causas do desaparecimento do guará em Guaratuba, "R 7" respondeu: "Eu não sei, não tenho a mínima ideia." Já "R 13" respondeu: "Ele sumiu? Eu nem sabia que esse bicho existia. Por acaso não é aquele lobo que a gente ouve falar que existe por ai na mata?".

As respostas deixam claro que para esses ribeirinhos a ave guará representa pouco ou quase nada, tanto na esfera individual como na coletiva de suas práticas sociais. No imaginário dessas pessoas o guará não tem representação. E o seu retorno à Baía de Guaratuba, depois de um período tão grande de desaparecimento, não tem nenhum significado.

Segundo Jodelet (2009), os significados que os sujeitos individuais e coletivos atribuem a um objeto do seu meio social e material estão ligados à sua sensibilidade, seus interesses, seus desejos, suas emoções e seu funcionamento cognitivo. E essas demonstrações dos participantes da pesquisa, entende-se, são capazes de despertar-lhes a sensibilização, em especial devido às práticas das atividades de Educação Ambiental. 
O participante "R 18" demonstrou o quanto há de falta de interesse, de desejos e de emoções quando perguntado sobre quais as possíveis razões do retorno do guará a Guaratuba: "Eu não sei não, moças. Acho que ele ficou com saudades das águas do Paraná, por isso voltou". E essa atitude foi reforçada por "R 2" que, ao ser questionada sobre quais atitudes poderiam garantir a preservação da ave no município, respondeu: "Eu não sei, e não posso fazer nada, moro aqui longe de tudo $e$ já estou velha”.

Ambos os ribeirinhos demonstraram, em suas respostas, não possuírem nenhum tipo de conhecimento ou de interesse sobre a ave guará, sobre suas relações sociais com a localidade e sua população. Também fica evidente, diante de suas respostas, um total abandono e descaso quanto à preservação, seja do guará, seja de qualquer outra espécie animal.

\subsection{O belo e a beleza - a beleza dos guarás}

O belo e sua decorrência, a beleza, foram expressivamente enfatizados em razão do esplendor do guará. De fato, o guará é considerado por muitos especialistas como uma das mais belas aves do planeta por possuir penas em tom de vermelho púrpura, que o destacam das demais aves do manguezal, podendo, desta forma, ser avistado e reconhecido de longe por qualquer simples observador (Olmos \& Silva e Silva, 2003).

A beleza do guará, em especial da sua plumagem, se comparada a outras aves do manguezal, desperta inúmeros sentimentos e emoções nas populações que convivem no seu habitat. E a população do município de Guaratuba, participante da pesquisa, convive com essa condição de beleza natural no seu dia a dia (Figura 3).

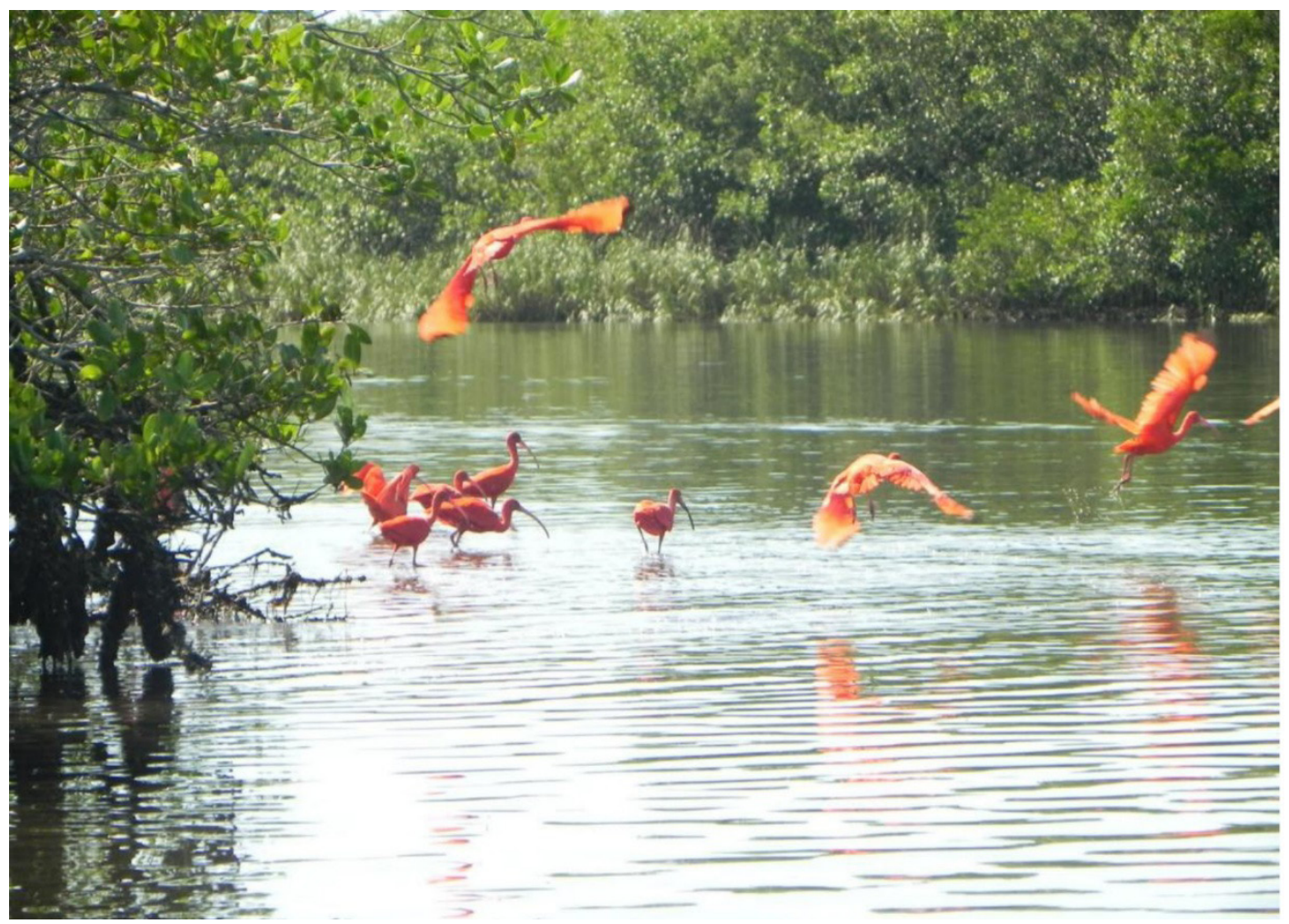

FIGURA 3 - Guarás residentes na Baía de Guaratuba (maio de 2012).

FONTE: Imagem cedida pelo Instituto Guaju - Guaratuba (PR). 
Para parte dessa população pesquisada, o fato de ter a possibilidade de observar e conviver com uma ave tão bela, há muito desaparecida, é motivo de contentamento e satisfação. A carga emocional fica evidente nas falas de alguns participantes, em especial daqueles residentes nas localidades Fincão e Parati.

A participante "R 22", relata:

Eu e meu marido, minha cunhada e meu irmão saímos de barco pela baía, a gente tava (sic) testando um barco novo. De repente, vimos aquele pássaro tão lindo parado ali. Fiquei emocionada, ele é lindo, lindo, lindo demais, a gente se emocionou. Quando eu era criança, aprendi na escola que o guará era o símbolo de Guaratuba, e agora a gente pode ver ele depois de tanto tempo que ele ficou sumido daqui. A gente acaba se emocionando muito. Mas ele é muito lindo, vermelho como sangue.

Para essa moradora ribeirinha, esse primeiro contato com o guará despertou-lhe inúmeras emoções e trouxe-lhe à tona vários sentimentos, que até então ela não havia experienciado. Esses sentimentos despontam, especialmente, pelo fato de o guará ter estado desaparecido por tanto tempo da Baía de Guaratuba e hoje não mais fazer parte da realidade diária dessa comunidade.

Tuan (1980, p. 110) esclarece:

O despertar profundo para a beleza ambiental normalmente acontece como uma revelação repentina. Este despertar não depende muito de opiniões alheias e também em grande parte independe do caráter do meio ambiente. As cenas simples, mesmo as pouco atrativas, podem revelar aspectos que antes passavam desapercebidos e este novo insight na realidade é, às vezes, experienciado como beleza.

Sem dúvidas, as mais intensas experiências estéticas com a natureza normalmente nos apanham de surpresa (Figura 4). E, como ressalta Tuan (1980), com a surpresa, a beleza se revela e é sentida como um aspecto

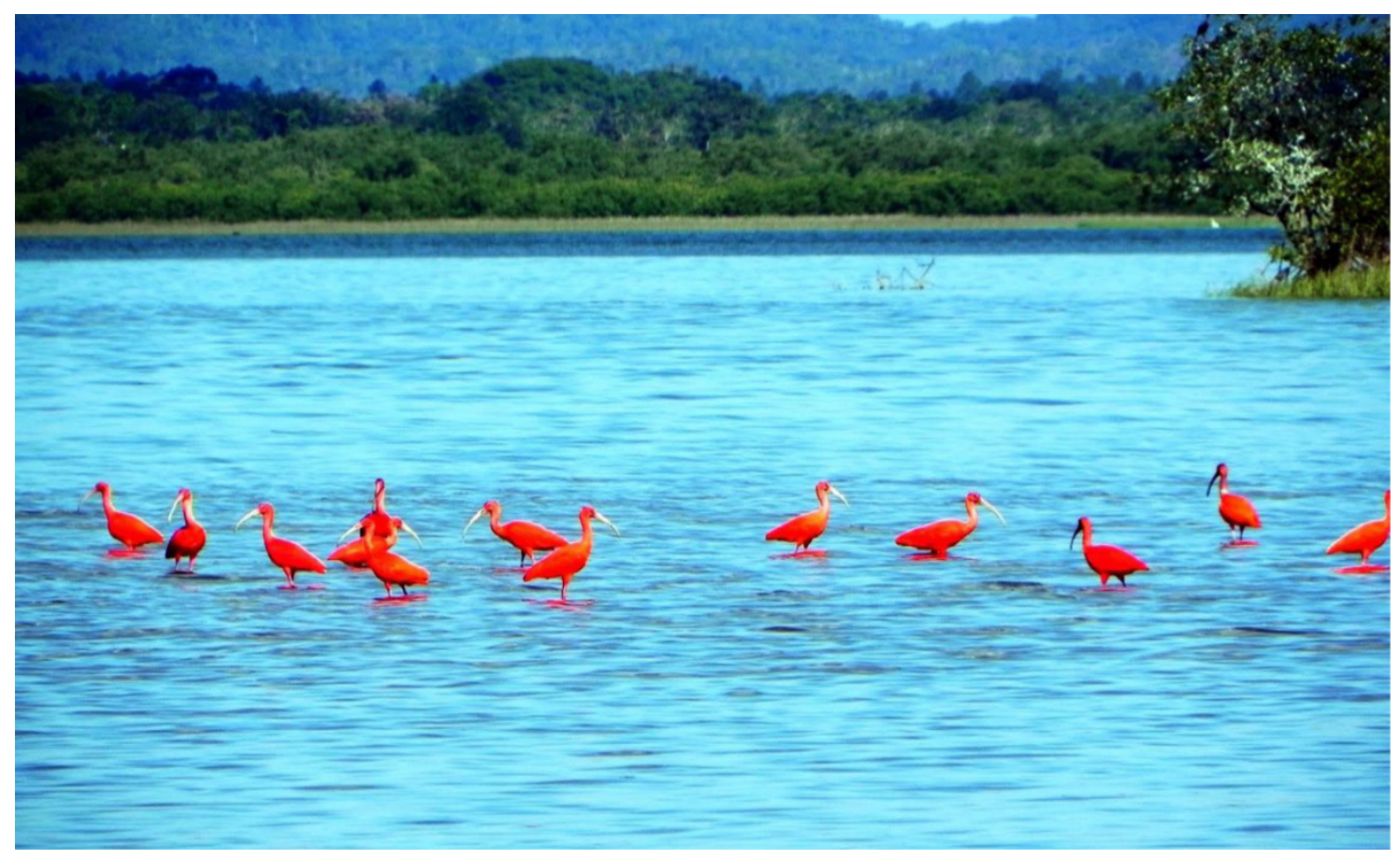

FIGURA 4 - Bando de guarás na Baía de Guaratuba - 2011.

FONTE: Imagem cedida por Fabiano Cecílio da Silva, Guaratuba. - PR (acervo particular). 
da realidade até então desconhecido, contrapondo-se ao gosto desenvolvido por certas paisagens ou locais já conhecidos.

\subsection{O símbolo de Guaratuba - o guará}

Esta é a expressão para o guará: “o símbolo de Guaratuba”. Para a maioria dos participantes da pesquisa, o guará é visto como um dos símbolos mais importantes da cidade, pois essa ave dá origem ao nome da cidade e representa Guaratuba nos seus vários atributos de beleza e exuberância (Figura 5). A imagem do guará está presente na Bandeira e no Brasão do município, além, ainda, de dar nome a tantos estabelecimentos comerciais na cidade.

Segundo a participante "R 34", "o guará é o símbolo da cidade, dai vem o nome Guaratuba". Já para o participante "R 38", "o guará é o símbolo de Guaratuba, você pode ver isso por aí, quando passeia pela cidade tem muitas imagens de guarás". Para ambos os participantes, é evidente que existe a percepção da existência de uma estreita relação entre a ave e a cidade.

Tuan (1980, p. 114) define que

a consciência do passado é importante no amor pelo lugar. A retórica patriótica sempre tem dado ênfase às raízes de um povo. Para intensificar a lealdade, se torna a história visível com monumentos na paisagem e as batalhas passadas são lembradas, na crença de que o sangue dos heróis santificou o solo. Os povos analfabetos podem estar profundamente afeiçoados ao lugar de sua origem. Eles podem não ter o senso ocidental moderno, mas quando procuram explicar sua lealdade com o lugar, ou apontam os laços com a natureza (o tema Mãe Terra) ou recorrem à história.

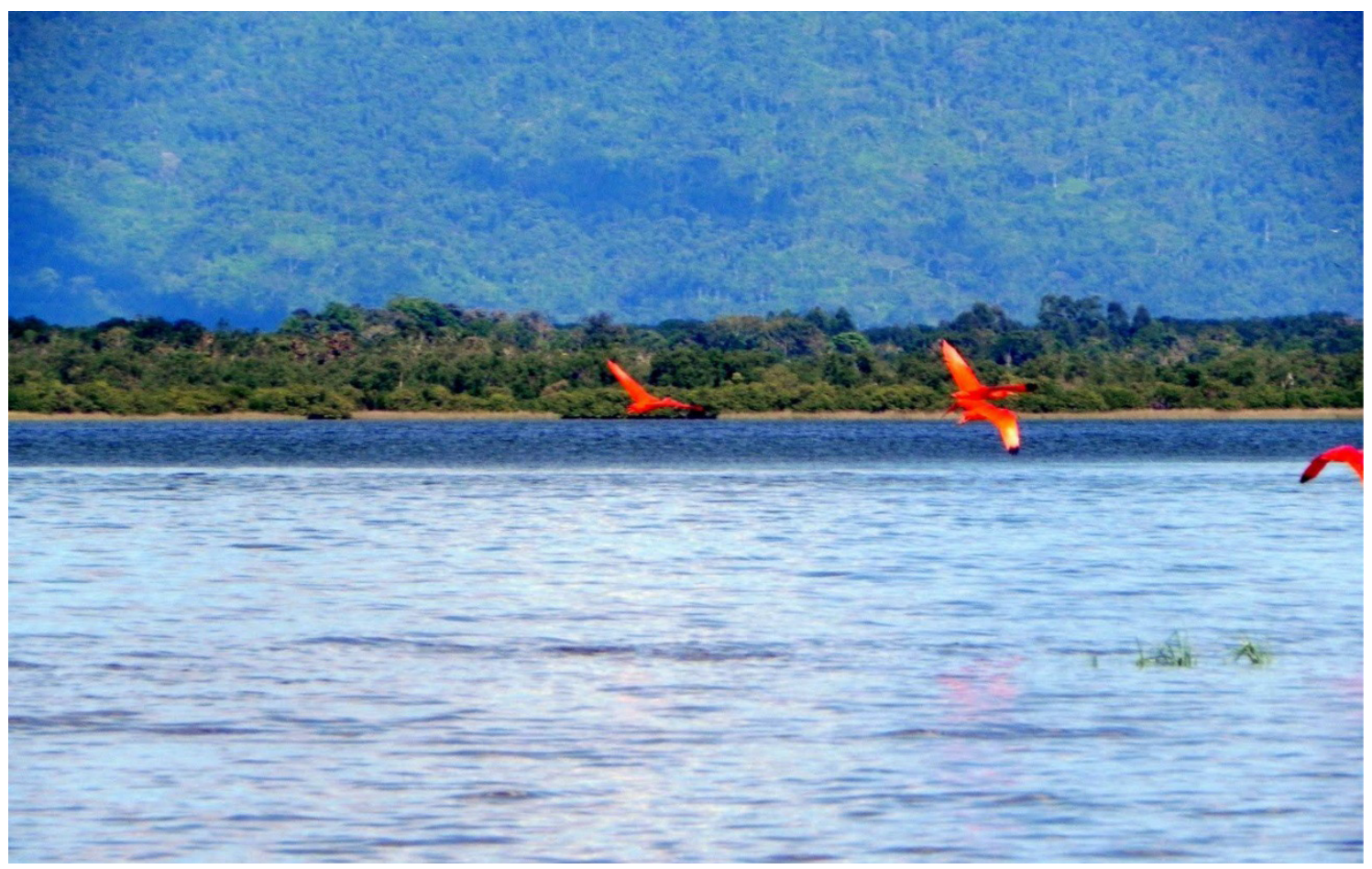

FIGURA 5 - Guarás sobrevoando a Baía de Guaratuba - 2011.

FONTE: Imagem cedida por Fabiano Cecílio da Silva - Guaratuba - PR (acervo particular). 
Nesse sentido, pode-se entender que os laços de afeto que a população de Guaratuba estabelece com o guará tornam a ave um dos principais símbolos da beleza e da exuberância natural da localidade.

\section{Considerações finais}

Durante a aplicação da pesquisa foi-nos possível identificar, nos grupos estudados, que, dependendo do local de residência, do nível de escolarização e da exposição do sujeito ao conhecimento, representações sociais diferentes emergiam das expressões do imaginário desses grupos em relação à ave guará. De um lado, sentimentos de contemplação da beleza do guará e, de outro lado, a manifestação do desconhecimento em relação à presença da ave na localidade.

O desconhecimento da existência do guará em Guaratuba é um fator preocupante, pois é necessário que os sujeitos estejam sensíveis às causas ambientais

\section{Referências}

Andrade Junior, H.; Sousa, M. A.; Brochier, J. I. Representação social da Educação Ambiental e da Educação em Saúde em universitários. Psicologia: Reflexão e Crítica, 2004, 17(1), 43-50. Disponível em: <http://www.scielo.br/pdf/\%0D/prc/ v17n1/22304.pdf>. Acesso em: 26/05/2011.

Baldin, N.; Albuquerque, C. (Orgs). Novos desafios na educação: responsabilidade social, democracia e sustentabilidade. Brasília: Liber Livro, 2012.

Bardin, L. Análise de conteúdo. São Paulo: Edições 70, 2011.

Carrano, E.; Scherer Neto. P. Guará. Planos de Conservação para Espécies de Aves Ameaçadas no Paraná. IAP/Projeto Paraná Biodiversidade, Curitiba, 2009, p. 31-39. Disponível em: $<$ http://www.redeprofauna.pr.gov.br /arquivos/File/Avesweb. pdf $>$. Acesso em: 23/03/2011.

Departamento de Cartografia da Univille. Imagem. Joinville: Univille, 2013.

Elias, N. Envolvimento e alienação. Rio de Janeiro: BCD União de Editoras S.A., 1998.

Ferreira, N. T.; Eizirik, M. F. Educação e imaginário social: revendo a escola. Em Aberto, Brasília, 14(61), jan./mar. 1994. para que possam atuar de modo mais expressivo na garantia da preservação de espécies ameaçadas, como é o caso do guará na área estudada. E mais, é importante ainda acrescentar que, segundo Jodelet (2009, p. 699), “as representações sociais estão ligadas às experiências sociais dos grupos e aos locais e tempo em que os sujeitos estão inseridos, e isto se reflete diretamente em como esses indivíduos se relacionam com o meio onde vivem".

Nesse entendimento, o quadro que despontou da pesquisa possibilitou-nos a percepção que de fato é fundamental o desenvolvimento de ações e práticas de Educação Ambiental junto às comunidades ribeirinhas de Guaratuba. Ações que possibilitem, aos moradores locais, a reflexão sobre as suas práticas cotidianas e sobre como podem se relacionar com as outras criaturas - todas, com as quais compartilhamos o planeta. E, no caso do estudo aqui em destaque, particularmente de como a população de Guaratuba convive e poderá vir a conviver com o guará que retorna às águas da sua baía.

Disponível em: <http://www.rbep.inep.gov.br/index.php/ emaberto/article/viewFile/907/813>. Acesso em: 12/07/2011.

Floriani, D.; Knechtel, M. R. Educação Ambiental, epistemologia e metodologias. Curitiba: Vicentina, 2003.

Guimarães, M. (Org.). Caminhos da Educação Ambiental: da forma à ação. Campinas (SP): Papirus, 2006.

Instituto Guaju. Imagens. Guaratuba: Instituto Guaju, 2012.

Jacobi, P. Educação Ambiental: o desafio da construção de um pensamento crítico, complexo e reflexivo. Educação e Pesquisa, São Paulo, 31(2), 233-250, maio/ago. 2005. Disponível em: $<$ http://www.scielo.br/pdf/\%0D/ep/v31n2/ a07v31n2.pdf $>$. Acesso em: 30/07/2012.

Jodelet, D. O movimento de retorno ao sujeito e a abordagem das representações sociais. Sociedade e Estado, Brasília, 24(3), 679-712, set./dez. 2009. Disponível em: $<$ http://www.scielo. br/pdf/se/v24n3/04.pdf > . Acesso em: 12/08/2011.

Lüdke, M.; André, M. E. D. A. Pesquisa em Educação: abordagens qualitativas. São Paulo: Editora Pedagógica Universitária, 2007. 
Mafra, J. História do município de Guaratuba. Guaratuba: s.e., 1952.

Olmos, F.; Silva e Silva, R. Guará: ambiente, flora e fauna dos manguezais de Santos-Cubatão Brasil. São Paulo: Empresa das Artes, 2003.

Primack, R. B.; Rodrigues, E. Biologia da conservação. 1. ed. Londrina: Planta, 2001.

Reigota, Marcos. Meio ambiente e representação social. 7. ed. São Paulo: Cortez, 2007.
Serbena, C. A. Imaginário, ideologia e representação social. Cadernos de Pesquisa Interdisciplinar em Ciências Humanas, 52, dez. 2003. Disponível em: <http://ger.ufsc.br/index.php/ cadernosdepesquisa/article/viewFile/1944/4434>. Acesso em: 20/06/2011.

Silva, F. C. Imagens. Acervo particular. Guaratuba (Paraná), 2011.

Tuan, Y. Topofilia: um estudo da percepção, atitudes e valores do meio ambiente. São Paulo: Difel, 1980. 